\title{
Estética del Arte Indio
}

\author{
Javier huidobzo Perzez-VILLamil
}

Bajo el término arte indio englobamos una cultura de cinco mil años, desde los origenes de la Cultura dei Indo (3000-1500 a. C.) a nuestros dias. Durante todo este tiempo se suceden pueblos, estructuras sociales y religiones, formando una de las culturas más ricas hasta hoy conocidas'. Centrare este estudio en algunas consideraciones estéticas de este arte que pueden relacionarse con aspectos correlativos del arte occidental?

Dentro del ciclo de las reencarnaciones, el sentido de la vida en la sociedad india da más valor a los conceptos abstractos y generales que a los hechos individuales y concretos. Lo verdaderamente real y válido tiene un sentido trascendente mientras que el suceso puntual se entiende como irrealidad, manifestación insignificante de un tipo general ${ }^{3}$. En la hipervaloración de una realidad abstracta varios autores han planteado similitudes

Hasta 1924, la historia del arte en la India no podia remontarse más alla del sigio iv a. C. fecha de la invasion de los ejercitos de Alejandro Magno por el noroeste, pero desde 1931. las investigaciones y exploraciones arqueologicas demostraron la existencia de culturas anteriores. Cronologicamente se suceden: Cultura del Indo (3000-1500 a. C.). Invasión Aria 11500-300 a. C.). Dinastia Maurya (siglo : a. C.). Estilos de iransicion 150 a. C. -320 d.C., con el Ghandara o Grecobudico. Mathura, y Amaravati). Arte Gupta (320-490-650 d. C.), Arte Pallava (650-750 d. C.). India Medieval (siglos ix xv d. C.). y Periodo Mogol.

Todo parece indicar que proximamente se crearán titularidades de Arte Oriental en Macirid y Barcelona. Hasta el momento. ios estudios orientales siguen considerandose en Espa. na como algo exótico

"... en la India se ha dicho que todas las canciones por igual, ya sean sagradas o profa nas, se refieren a Dios, y que sólo El es el verdadero maestro que revela la presencia dé Espiritu supremo (pramatan) dondequera que la mente se aplique (...) No es necesario decir que estas concepciones del mundo como teotania no se pueden distinguir en nada de las basadas en las tradiciones platonica y escolastica*. A. K. Coomaraswamy. Sobre la doctrina tradicional del arte. Ediciones de la Tradición Unánime. Barcelona 1983. 
con el pensamiento de Platón. Este filósofo griego consideraba también como real aquello que pertenecia a un ámbito trascendente, inmutable, prototipo ideal de lo percibido por los sentidos ${ }^{4}$. Por su parte, el artista indio, a la hora de representar una imagen sagrada, recurre a la contemplación de una Forma que es la única que posee tanto una plena realidad como una parte de las cualidades atribuibles a lo sagrado. ${ }^{5}$. En este alejarse de una visión mimética de la naturaleza, y en la tendencia hacia la Forma ideal se plantea la relación con el método operativo del artista griego $^{6}$. Este último, al ser interrogado sobre cómo podia conocer la manera exacta en que pasaron los hechos que narra y hasta los sentimientos experimentados por los personajes de su historia, recurría a la autoridad de las Musas que le habian permitido superar la barrera del tiempo y del espacio y ver las cosas tal y como fueron. El griego se siente arrebatado por un furor divino que hace posible el acto creador.

El artista indio experimenta también un cierto arrebato que le aleja del entorno sensible, pero a este estadio superior llega mediante un proceso diferente al seguido por el griego, por un camino de purificación interior que lleva implicito un perfeccionamiento de si mismo, tanto por la eliminación de cualquier perturbación exterior como por la contemplación de la imagen divina. Es pues, un proceso interior, no exterior como en Grecia, y con una función regeneradora inexistente en el método griego.

La naturaleza del camino seguido por el artista indio permite que la visión ofrecida de la Forma ideal tenga un carácter fundamentalmente objetivo. Lo que se nos ofrece no es la visión personal del artista sino la verdadera imagen tal como es.

Más coherente seria, por tanto, establecer el paralelismo con la imagen ideal platónica, entendida como algo perfecto e inmutable cuya visión habria de ser necesariamente objetiva. Sin embargo, en el proceso de

4 En el sentido griego de un ámbito de Formas, de perfección e inmutabilidad; no en el hegeliano. Asimismo lo material es considerado como copia imperfecta de lo ideal y por tanto irreal.

* "El concepto de prathiba (que podria traducirse por "intuición creadora») se entenderia como expresión creadora, palabra, tesoro de formas nuevas, realisimas, pero distintas de las que pueblan la vida cotidiana, el samsara; y la intuición arística se proponia como una "hipostasis especial de la intuición universal o total, es decir, de la consciencia como fuerza que crea y renueva continuamente el universo"» (cita de R. Got.) en U. Eco, La definición del arte, Martínez Roca, Barcelona 1970 (Milán 1968).

- Asi, Cicerón en Orator, 9 comenta de Fidias que al dar forma a su Zeus y su Atenea no contemplaba ningún modelo humano del que tomar un parecido, "sino que mas bien tenia en su imaginación alguna visión extraordinaria de belleza", y que "fijando en elia su atención dirigio su mano a tomar de ella su forma», J.J. Pollit. Arte y experiencia en la Grecia Clasica. Xarait, Madrid 1984 (Cambridge 1972). 
conocimiento platónico, cuando se alcanza el último grado, la noesis, el individuo no pierde su individualidad, su objetividad. Sólo en el neoplatonismo (Plotino) encontramos un proceso cognoscitivo que, terminando en una reabsorción, admite una pérdida de la consciencia individual. Ahora bien, en el ámbito de lo sensible nunca podria darse una copia perfecta del modelo, lo que provoca la condena platónica al arte. La finalidad religiosa y la exactitud de la copia en el arte indio explican la no aparición de una condena semejante ${ }^{7}$.

Según la tradición hindú, toda forma posee una cualidad esencial, la luz, ruci o radiación de la belleza, comparable a la luminosidad de Platón y Plotino, en quienes el tipo supremo de las Formas se compara con el Sol. Esta luminosidad de la belleza emana de los humanos y de las cosas y sólo cuando estas dos radiaciones están en perfecta armonia es cuando los objetos aparecen en toda su belleza. En caso contrario se produce una sensacićn de fealdad. Lo sensible adquiere por tanto un valor positivo en la consecución de la belleza, a diferencia del rechazo platónico del mundo contingente ${ }^{8}$.

La realización de la obra de arte suponia una doble via de purificación, primero para el artista con su proceso de accesis previa, y segundo para el espectador que medita con y gracias a la obra sagrada. En el mundo pitagórico la contemplación y experimentación de la armonia es asimismo una via de perfeccionamiento. Pollit señala que para los pitagóricos la contemplación de la armonia numérica tenía una finalidad espiritual: con-

La exactitud de la copia viene dada por el valor sagrado de la imagen plástica y por la adecuación a unos cánones iconográficos preestablecidos,

"... de la imitación de principios divinos y eso puede hacerse solamente si se conocen estos principios "tal y como son" y no según nuestra opinión; de aqui la necesidad de la contemplación (samadhi) para producir una obra de arte, es decir, que la obra de arte no es una fracción de la belleza universal, de Dios, sino un reflejo, una semejanza, similitudo (pratimba en sánscrito)". J.R. RIVIERE, "Introducción a la estética del arte de la India", Boletin de la Asociación Española de Orientalistas, año IV. Madrid, 1968.

De igual forma: "But whereas Platonic types are type of being, external to the conditioned universe and thought of as absolutes reflected in phenomena, Indian types are those of sentient activity or funtional utility conceivable only in a contingent world. Oriental types, Indian Siva-Sakti. Chinese Yang and Yin, or Heaven and Hearth, are not thought of as mechanically reflected in phenomena, (...) Thus Indians types representing sentencies or powers which we "explain" phenomena, (...) Thus Indiars types representing sentencies or powers are analoguos to those of Scholastic theology and the energies of science, but not comparable with Plato's types". A.K. CoOmaraswamr. The transformation of nature in art, Dover, New York, 1975

${ }^{8}$ Esta valoración positiva de lo percibido por los sentidos se explica por la creencia budista según la cual no habia que renunciar a los sentidos sino más bien usarlos como primer paso de una elevación espiritual que tiene como fin la unión con los dioses y los ideales. 
templar las pautas divinas era un medio de purificar el alma y prepararse para una forma de existencia superior ${ }^{9}$.

Umberto Eco ha señalado la posible relación existente entre el concepto indio de Rasa o Quintaesencia del Gusto, según la explicación de Bhata Lollata, y la catarsis aristotélica, según intereses psicológico-terapéuticos del tipo de la cura homeopática ${ }^{10}$. Para algunos autores, la causa final de la tragedia en Aristóteles es la purgación ritual, viendo en la tragedia una finalidad moral: la purificación de las emociones; otros autores entienden la palabra catarsis como una metáfora sacada de la purgación de los humores corporales malignos, y ven en el objeto de la tragedia una cualidad no moral ${ }^{11}$. En todo caso, en el arte indio tiene lugar un proceso similar a la catarsis aristotélica al producirse en el espectador una exaltación anímica: mediante la contemplación de la obra de arte el hombre indio experimenta un wroceso de purificación similar al del artista. Aristóteles define en la tragedia una ceremonia que no sólo tiene naturaleza estética sino también una clara función social, incluida la presencia de técnicas dionisicas; la representación dramática aparece como instrumento de educación empírica de las pasiones.

Más aceptable parece la analogía establecida por Chaudhury entre la teoria médica del rasa y la teoria médica de los humores y del gusto tal

${ }^{9}$ POLLit, op. cit. Debe señalarse que en el pitagorismo no hay una teoria del arte sino una teoría del conocimiento.

${ }_{10}$ ECO, op. cit.

"La primera teoria tiene el apoyo de autores como Lessing. La segunda se difundió sobre todo despues del Renacimiento y fue argumentada por Bernays.

"Que la tragedia provoca la piedad y el temor es un hecho bien conocido, y era una de las razones en la cual Platón se fundaba para atacarla; estimulando la emoción, decía, la tragedia nos vuelve más emotivos y más débiles. Aristóteles le responde implicitamente que el objeto final de la tragedia es, no volvernos más emotivos, sino purgarnos de nuestras emociones. (...) Aristóteles no considera bueno para el hombre estar enteramente libre de toda tendencia al temor y a la piedad; "hay cosas a las cuales debemos temer" y cosas que deben inspirarnos piedad. Eso significa "su remocion en la medida en que ellas son un exceso"»W.D. Ross, Aristóteles, Editorial Sudamericana, Buenos Aires, 1957.

Ross presenta una teoria intermedia, expresada por Milton. Aristoteles habria pretendido que provocando la piedad o el temor, o el terror, la tragedia tenia el poder de purgar el alma de estas pasiones y de pasiones parecidas; es decir, de atemperarlas o de reducirlas a una justa medida por el placer particular que produce la lectura o el espectáculo de una buena imitación de estas pasiones. Asi, en la medicina, las cosas de tinte melancólico sirven para combatir la melancolia, el ácido para curar la acidez y la sal para expulsar los humores salados.

Según Eco, op. cit., pág. 77: “Aristóteles hubiera aceptado fácilmente la concepcióri india de una contemplación de la esencia de las cosas. La tragedia tiene una función medicinal sólo en el sentido de que impulsando a ver la esencia de las cosas lleva al espectador a la más elevada condición, que es la de la racionalidad, (...) los escritos del filósofo griego sobre la piedad y el terror no permiten una lectura que excluya a priori una referencia a la concepción médica de la catarsis". 
como se encuentra en Hipócrates, señalando la analogía entre rasa y reos $^{12}$

Coomaraswamy establece una relación entre la apariencia externa (rupa, el cuerpo) y la realidad interior del iluminado (nama, el nombre). Así aparece en el Corpus Herméticum, lib. XIII, en un diálogo entre Hermes y su hijo: Hermes niega que Asclepios, que está efectivamente mirando a su padre, pueda verle en realidad' ${ }^{3}$. En el Chadogya Upanisad se diferencia claramente entre la persona espiritualmente esencial y el ego empírico. El todavia no regenerado Asclepios (como Bharata en el Pratimanataka) no logra reconocer a su propio padre en esta imagen espiritual de la que habla.

Algunas cuestiones formales han sido puestas de manifiesto en torno a las artes griega e india. La desnudez de la figura masculina, patente en Grecia desde el periodo geométrico (siglos $x$-vill antes de Cristo), característica de la actitud religiosa de los griegos, aparece asimismo en el arte indio. Los torsos de Harapa, en el 2000 antes de Cristo, de la civilización del Valle del Indo, cuando en Occidente aún dominaba el Neolítico, dejan abierto el interrogante sobre el orígen de la figura sagrada desnuda en bulto exento de grandes dimensiones. Aunque la concepción india del significado de la naturaleza y del desnudo pudieron originar de motu propio en la India la figura desnuda, varios autores han destacado la existencia de un fondo común europeo que relaciona esta cultura con la griega ${ }^{14}$.

"Quizá la forma rnás práctica de que los occidentales comprendamos esta "verdadera grandeza" es compararla con lo que los romanos llamaron divinus afflatus, el soplo divino que dota a la obra de una vida inmortal". C. Garcia-OAmaechea y J. HuDobro, "El arte indio como intento de hacer palpable lo divino y lo trascendental", Expresión artistica y Fe, Editorial Popular, Madrid, 1987, pgás. 77-78.

13 Scotr, Hermetica, ।, 241

"Veo que, por la misericordia de Dios, ha nacido en mi una forma que no está hecha de materia.. No soy ahora el hombre que era; he nacido de nuevo en la Mente, y la figura corporal que antes era mia ha sido separada de mi. Ya no soy un objeto de color y tangible; una cosa con dimensiones espaciales; ahora soy ajeno a todo esto y a todo lo que percibes cuando miras con la vista corporal. Para ojos como los tuyos, hijo mio, ahora "yo" no soy visible". A.K. CoOmaraswamy, La Filosofia cristiana y oriental del arte, Taurus, Madrid, 1980. pág. 123 (Dover, New York, 1965).

1. CAMON AzNAR, acerca del periodo que el llama "Cosmogónico" idel año 1000 al 700 a.C.) comenta la unidad sustancial e inseparable del hombre con la Naturaleza, la forma di vina, la humana y la natural forman la misma unidad que se puede apreciar en el mundo indio.

"Esta cultura no concibe al hombre exento y desgajado del alveolo de naturaleza al que está adscrito. (...) Por eso, cuando se le representa con tal conciencia artistica, como en la Hera de Samos, se le funde con aquellos elementos naturales más congruentes a su forma. No es que el tronco de árbol imponga la forma de la diosa. Es que los miembros divinos estan sumidos en esta forma natural, porque la sensibilidad de la época exigia esta indiferenciación. (...) El tronco de árbol es la forma más capaz de ósmosis con el cuerpo divino. La unidad sustancial del Universo se concreta en esta imagen pura." J. CAMON AzNAR. Teoria del arte griego, Salvat, Barcelona, 1975. pág. 23. 
Como la india, la forma desnuda helénica es imagen del hombre que ha superado las contingencias de la vida terrestre. A esa misma familia indoeuropea podemos adscribir la llamada sonrisa ramosiana, tal como la denomina J. Auboyer, aparecida en Grecia, Egipto y la India; asi también el rito de insuflar la vida en las esculturas indias es similar al rito de abrir los ojos del arte griego en que las esculturas recibian ojos de un material brillante.

Aunque se presta a discusión, el sistema de proporción antropomórfica del arte indio es más parecido al egipcio. El canon policlético no pretende la simetria de los elementos sino de los números (no de las parte sino de la relación entre ellas) ${ }^{15}$. El módulo antropomórfico indio, la thalam, correspondiente a la medida entre el alto de la frente y el mentón, no modifica la dimensión de una parte con respecto a las demás, sino que marca un sistema de medidas según un módulo fijo; algo mucho más cercano a la retícula cuadriculada egipcia ${ }^{16}$. Sin embargo, parece griega la autonomia de las partes del cuerpo humano: cada una se asimila a una intención determinada contribuyendo a una idea global de la forma física representada.

No se ha encontrado ningún rasgo de arquitectura griega en la India, es decir, ningún edificio de la India fue diseñado según un plan griego ni existen referencias de utilización de alguno de los órdenes griegos. Pero los arquitectos hindo-helénicos del arte greco-búdico de Ghandara usaron libremente formas arquitectónicas griegas degradadas con fines decorativos. La abundancia de columnas corintias modificadas, pilastras y capiteles en el arte de Ghandara contrasta con la total falta de dórico y la extrema rareza de las formas jónicas. La mayoria de los frisos de Ghandara muestran representaciones de columnas o pilastras con capiteles más o menos referidos a los del orden corintio, los cuales han llegado a denominarse indo-corintios. Estos capiteles concuerdan con el estilo lujoso cosmopolitano en boga a través del Imperio Romano durante los primeros siglos de la era Cristiana.

G. Reale comenta el encuentro de Alejandro y su séquito, en el que se encontraba Pirrón, con la secta de los Gimnosofistas de la India, quienes llevaban una vida de tipo monástico dedicados a la superación de las pobrezas humanas y a la conquista de la impasibilidad. Esta secta causó una gran impresión entre los griegos: Onesicrito creyó volver a encontrar

\footnotetext{
15. "...de dedo a dedo, y de todos ellos en relación con la mano y la muñeca, y de éstas con respecto al antebrazo, del antebrazo con respecto al brazo y de todas las partes con respecto a todo". Robertson, El arte griego, Alianza, Madrid, 1985, pág. 214.

16 Ver E. Panofsky, El significado de las artes visuaies, Alianza Forma, Madrid, 1979.
} 
el ideal de la filosofia cinica ${ }^{17}$. El grado de pureza y ausencia de perturbaciones que se le exige al artista indio puede ser relacionado con el concepto de ataraxia epicurea o la afasia de Pirrón, en donde no es dificil ver las influencias de los Gimnosofistas y de Calano.

Tanto en el arte indio como en el medieval el concepto de belleza es inseparable del criterio de verdad. El fin del artista no es la belleza de la obra de arte sino reflejar al máximo el tema representado. En Occidente, esta concepción de la belleza perdurará durante el Renacimiento y el Barroco (recordemos a Savonarola y al padre Martin de Barcos, por ejemplo). No podemos olvidar, sin embargo, que la belleza no es un valor secundario en estas artes que Coomaraswamy llama tradicionales. El arte debe no sólo enseñar, sino también conmover para convencer. Los dos sentidos de interrelación entre lo humano y lo supraterrenal, el analógico (la participación de la Belleza verdadera en la Belleza sensible) y el anagógico (lo sensible como primer paso hacia la Verdad última) están presentes tanto en el arte medieval como en el arte indio ${ }^{18}$.

Eco destaca la existencia en la literatura india de textos fundamentales que permiten una diferenciación, aunque no radical, entre placer estético y proceso de conocimiento místico ${ }^{19}$. Los criterios de belleza en la India se asemejan también a los medievales occidentales. Lo bello es lo ordenado, lo armonioso según ciertas relaciones entre las partes de una ubra de arte. La perfección consistirá en ese poder de atracción que reside en toda obra bella, según unos principios formales de marcado contenido simbólico e ideal. En este idealismo, de carácter intelectual, impersonal y sagrado, el arte oriental y el cristiano medieval tienen otro elemento en común; frente a la representación naturalista que aparece con frecuencia en el occidente europeo, el arte oriental representa una condición continua, una proximidad con las cosas tal como ellas aparecen en Dios, como son en origen.

G. Rfalf, Storia della filosofia antica, Vita e Pensiero, Milán, 1980

"Según el punto de vista medieval, no se podia coinprender nada que no se hubiera experimentado. o amado". A.K. Coomaraswamy, La filosofia cristiana.... pág. 115.

" Un conocimiento profundo de la estética india (...) nos demuestra cómo incluso en un clima de caldeado ambiente mistico se puede conceder a la experiencia estética un carácter estrictamente terrenal, $(. .$.$) la estética india nos asombra por la madurez alcanzada cuando$ entre nosotros la primitiva escolástica estaba todavia uniendo laboriosamente motivos dispersos para producir categorias muy generales. En el siglo $x$ de nuestra era el pensamiento indio habia desarrollado una serie de razomamientos acerca de la naturaleza del discurso poetico y de la intuición artistica que el pensamiento occidental no ha sistematizado criticamente hasta estos dos ultimos siglos. (...) Creemos que esta prioridad estética de la especulacion oriental se debe al hecho de haber unido decididamente la experiencia poética a la mistica". U. ECO, op. cit., págs. 78-79. 
Durante el proceso previo a la realización material de la obra de arte el artista indio logra la fusión ritual con la divinidad, llegando a identificarse con la forma ideal que quiere representar. Este estado de no diferenciación ha sido puesto en relación con el pensamiento escolástico medieval ${ }^{20}$. Sin embargo, en la escolástica tomista no hay ninguna identificación entre sujeto y objeto, manteniéndose la plena individualidad y consciencia del primero. Algo de esta fusión puede encontrarse en la interpretación aristotélica árabe (Averroes), a través de una corriente subterránea neoplatónica (Juan Escoto Eurigena), pero no en la escolástica propiamente dicha, que mantiene una concepción objetivista en la que el sujeto y el objeto son diferentes tanto en el conocimiento como en la experiencia moral y religiosa: no hay fusión entre hombre y Dios.

Más allá de la relación manifiesta, el artista medieval no llega, en el proceso cognoscitivo de la forma que va a representar, a la absoluta indiferenciación pánica india. El artista indio experimenta un proceso soteriológico, con fines tanto terapéuticos como teoréticos, en el cual pierde su individualidad, su subjetividad, diluyéndose en la forma representada ${ }^{21}$.

En cuanto a los elementos iconográficos son numerosos los paralelismos planteados entre ambas culturas. Todas estas formas comunes a ellas parecen haber sido elaboradas sobre un mismo sustrato mediterráneo y asiático. Temas orientales que influyeron sobre el helenismo y temas helenisticos que pasados a las civilizaciones orientales sobrevivieron ininterrumpidamente en los focos lejanos al abrigo de las convulsiones de la Edad Media, y vuelven a circular entre los mundos enriqueciendo el occidente cristiano 2 .

"El tad-akarata sanscrito corresponde al adaequatio rel et intellectus escolástico". J.R. RIVIFAE, op. cit.. pág. 68

Coomaraswamy recoge y aumenta este paralelismo tomando las afirmaciones de autores como Dante ("quien pinta figura si no puede ser el mismo no la puede concebir»), o Leonardo ("el pintor se pinta a si mismo").

Ver Roger Lipsey (editor). Coomaraswamy. selected papers. Traditional Ant and Symbolism. Princeton University Press. Princeton (New Jersey) 1986. Tarnbién: A. K. Coomaraswamy, The dance of Siva. Essays on Indian Art and Culture. Dover Publications, New York, 1985 (1924).

En la creación artistica medieval, el artista, sea o no protagonista. nunca pierde su conciencia personal, o en palabras de Eco: su "sentido occidental de las distinciones" (op. cit. pág. 68)

Los diversos tratados de estética india recuerdan que el artista para lograr el fin artistico debe aplicar los métodos de recogimiento tipicos del yoga. Con ellos el espiritu purificado puede producir la intuición generadora. En este caso se ha senalado un paratelismo con ciertas actitudes medievales en las que se exige al artista un estado de pureza interior cen el que puedan actuar los dones del Espiritu Santo", tal como aparece en la Schedula Diversarum Artium del abad TFofl.o. En este caso, la actitud requerida en el artista indio es mucho más radical.

"Condicionadas por el sistema greco-budico estas concordancias e identidades de ele- 
Asi podemos considerar la representación de las composiciones llamadas mandalas, que aparecen también en Japón y el Tibet, donde se integran en los ritos y ceremonias de culto. La cúpula del santuario de Kakrak, como tantos otros ejemplos, está decorada con ocho ruedas: una central y siete sobre una circunferencia. Cada una de ellas, forma una misma corona de círculos inscritos en otros representando la "aureola de los Cien Budas»; en estas especulaciones geométricas se representa todo el Universo. Occidente, a través de los astrónomos árabes que restituyen el fondo oriental, adopta las abstracciones y los símbolos esotéricos. Estas formas búdicas, superpuestas a las antiguas tradiciones islamizadas, multiplican las rotaciones, al tiempo que introducen algunos temas de encantamiento y revelación sagrada, como las evocaciones de los muertos, los diagramas en rosas, nombres y símbolos en un cosmos geométrico.

El ciclo de la Muerte, tal como se difunde por la Edad Media, tiene su expresión directa en la representación de cuerpos en estado de putrefacción y de esqueletos en pie. El final del Medievo está lleno de estas visiones de carnes descompuestas y esqueletos. Baltrusaitis y Huizinga han señalado cómo ambos temas tienen un inicial parecido con las concepciones budistas ${ }^{23}$. Sin embargo, la concepción medieval europea de la muerte es esencialmente distinta de la india, donde los muertos no son inhumados sino incinerados, con lo que no hay fantasmas en el arte indio. No hay resurrección de los muertos sino reencarnación. El paralelismo establecido por ambos autores es, por lo tanto, erróneo.

Asi, debemos cuestionar la relación establecida por Baltrusaitis del Encuentro medieval, motivo iconográfico según el cual, tres jóvenes encuentran tres cadáveres que les recuerdan la vanidad del mundo, con el pensamiento búdico: antes de la Gran Partida, Bodhisattva se encuentra sucesivamente con un viejo, un enfermo, un muerto y un eremita. Estos cuatro personajes del Encuentro búdico recuerdan, no la vanidad del

mentos favorecen ahora una nueva emigracion hacia Occidente. ¡Curioso destino el de este grupo de formas fantásticas que, tras su éxodo y larga estancia en culturas más estables. retornan a su lugar de origen!. Despues de haber pasado por la India. Asia septentrional y China, vuelven transfiguradas, cargadas de significación y leyendas y dispuestas a reintegrarse en la epopeya de Occidente". J. Ba trusaitis, La Edad Media fantástica, Cátedra. Madrid, 1983, págs. 250-251.

"El miedo a la vida: negación de la belleza y de la dicha, porque hay unidos a ellas colores y tormentos. Existe una asombrosa semejanza entre la antigua expresion india, budista, de este sentimiento y la cristiana medieval. Tambien en aquella se encuentra siempre el asco por la vejez, la enfermedad y la muerte, también los colores de la corrupción. Los ingenios estéticos de la India habian llegado a hacer de esto un género poético especial, bibhatsa-rasa o el sentimiento de los asqueroso. dividido en tres subgeneros. según que la repulsion fuese provocada por to repugnante, to espantoso o lo voluptuoso. El monje creia haber dicho todo lo que tenia que decir. mostrando la superficialidad de la belleza corporal." J. Hulzincia, El otoño de la Edad Media. Alianza Universidad. Madrid. 1978 (1930), pág. 198 
mundó cristiano medieval, sino el dolor mundano, determinando la decisión final de renunciar a las penas terrenales ${ }^{24}$.

Occidente toma de las representaciones de Buda los pedestales y los nimbos, enriqueciendo las posibilidades de representación de la figura humana. Frente al modelo medieval del nimbo opaco, de oro o materia dora$\mathrm{da}$, en el siglo $\mathrm{xV}$ se generaliza la presentación de nimbos transparentes, con los bordes marcados por uno o dos hilillos (Roger van der Weyden, Petrus Christus). Este motivo proviene del disco traslúcido de círculos aéreos del arte búdico: la cabeza aparece rodeada por una sombra luminosa que no oculta el fondo, viéndose el paisaje de forma ininterrumpida.

El episodio de las Tentaciones de San Antonio, nacido en Egipto y abierto a las influencias orientales, se relaciona con el de la Tentación de Buda según la visión oriental recogida por el Lalita-Vistara. Los excesos, aspecto pintoresco y deformidades de las Tentaciones occidentales presentan más afinidades con el carácter del texto indio que con las narraciones de los hagiógrafos cristianos. Para Baltrusaitis, la “Tentación” del Bosco del Museo del Prado se asemeja más a una visión búdica de demonios que a la leyenda cristiana ${ }^{25}$.

La representación multiplicada de los miembros del cuerpo humano es otro elemento común entre ambas culturas. La figura de la divinidad suprema, trifacial (una sola cabeza con tres rostros) o tricéfalo (un cuello con tres cabezas) aparece en el dios Shiva de un sello-amuleto de Mohenjo-Daro (3250-2750 a. C.), o en la llamada Trimurti de la gruta de Elefanta (siglo vıl d. C.). En el Medievo aparece este tema, como en un canecillo de la portada de Moissac, en el arte románico, o en el sepulcro del infante Alonso en la Cartuja de Miraflores en Burgos, en lo gótico. Los infiernos medievales representan estos elementos extremo-orientales, con figuras de brazos múltiples y tocadas con serpientes. Parece que Occidente reencuentra los monstruos gracias a los testimonios de los viajeros (la primera referencia directa la debemos a Marco Polo en 1272, al referirse a los idolos de la isla Cipango con varias caras y manos). El Bestiario de Gante (1479) sitúa a estos hombres de miembros multiplicados entre los seres monstruosos.

\footnotetext{
24 J. Baltrusaitis, op. cit., pág. 246.
}

25 "No se trata de una traducción o de una trasposición directa, sino de evocaciones, préstamos dispersos, vagas reminiscencias y concomitancias deseadas o espontáneas. Las cosas suceden en una misma esfera dinámica y todas las Tentaciones que han repetido estos temas acaban por fundirse». J. BALTRUSAITIS, op. cit., pág. 235.

Sobre los elementos artísticos comunes entre la India y Europa Occidental en la cultura artística del Renacimiento. Ver G. Muratore, La ciudad renacentista, Instituto de Estudios de la Administración Local, Madrid, 1980 (Milán, 1975). 
En la arquitectura, la influencia asiática llega asimismo a Occidente. En la India aparece el arco conopial (kudú) en las cavernas excavadas en la roca entre los siglos III y I antes de Cristo, coronando las puertas, las balaustradas y las falsas ventanas. Se ve también este arco en las fachadas de Ajanta (siglos V-VI). En Occidente, la contracurva conopial aparece en Inglaterra y Francia, donde los primeros arcos conopiales se muestran en los monumentos góticos como recorte del intradós (Hardingstone) y de los perfiles de los gabletes (Nivelles). Esta innovación, fechada entre finales del siglo XIII y principios del XIV, concuerda con la proliferación de las influencias orientales. 